\title{
Information Processing and Financial Market Price Adjustments
}

\author{
Edwin H. Neave1, William R. Scott ${ }^{2}$ \\ ${ }^{1}$ Bank of Montreal Professor Emeritus, Smith School of Business, Queen's University, Kingston, Ontario, Canada \\ ${ }^{2}$ Professor Emeritus, University of Waterloo, Waterloo, Ontario, Canada \\ Email: edwin.neave@queensu.ca
}

How to cite this paper: Neave, E.H. and Scott, W.R. (2019) Information Processing and Financial Market Price Adjustments. Theoretical Economics Letters, 9, 2337-2353. https://doi.org/10.4236/tel.2019.97148

Received: July 22, 2019

Accepted: September 23, 2019

Published: September 26, 2019

Copyright (c) 2019 by author(s) and Scientific Research Publishing Inc. This work is licensed under the Creative Commons Attribution International License (CC BY 4.0).

http://creativecommons.org/licenses/by/4.0/

\begin{abstract}
Using a model of heterogeneous investors' responses to changing information, this paper studies the impact of learning on equilibrium price changes. The paper develops the comparative statics of single period equilibrium conditions. It characterizes generally the variety of circumstances encountered in the literature.
\end{abstract}

\section{Keywords}

Ultraorthodox Interpretations, Price System

\section{Introduction}

Traditionally, finance theory has argued that securities prices are determined by publicly available fundamental (long run) information. However there are many conflicting findings. In this section we cite only closely related examples. More details are provided in the reference section. To cite selected examples, in the short run empirical estimates of risk neutral probabilities from option prices data display dynamic responses to changing market conditions (e.g. Figlewski [1]). In the longer run, observers attribute significant market events to differing causes. Campbell, Giglio and Polk [2] find that the price impacts of the 2000-2002 tech crash were due principally to changes in expectations (discount rates) while the initial price impacts of the 2007-2009 crash were due mainly to changes in fundamentals (cash flow forecasts). Moskowitz, Ooi and Pedersen [3] show that both time series momentum and value effects are commonly observed across nearly sixty different markets. In these markets, prices relative to fundamentals can remain unrepresentatively high - or low-for periods of up to a year.

This paper ascribes observed price behavior to the evolution of heterogeneous expectations that follow on public information releases. Many information 
events affecting securities markets are not interpreted unanimously by investors. Our model with heterogeneous investors enables us to investigate the effects of ambiguous information, regarded as good news by some investors, bad news by others. Information ambiguity is important, and drives most of our results.

\section{Passive and Active Responses to Prices}

In our single period model investors have heterogeneous expectations and equilibrium prices are established by a marginal investor. Non-marginal investors take these prices as given, defining an equilibrium with relatively straightforward properties. While the literature has not fully established the empirical nature of expectations change, Haltiwanger and Waldman [4] propose theoretical contexts in which the proportions of sophisticated to unsophisticated agents can have differential effects on equilibrium. Our model incorporates a spectrum of differently informed agents whose interactions determine equilibrium price adjustments.

The outline of the paper is as follows. Section 2 discusses relevant theoretical and empirical literature while Sections 3 and 4 present the single period equilibrium model. We determine equilibrium effects of changing probability estimates-assuming that investors agree on state-dependent payoffs. We can also determine comparative statics results for changes in payoffs.

\section{Review of Literature}

This section offers a sketch of research themes related to the paper's findings. This section is selective and focuses on closely relevant papers.

\subsection{Divergence of Opinion and Price Impacts}

To Edward Miller [5], heterogeneous expectations equilibrium implies an optimistic minority will invest in a risky security. Miller further notes that expected returns on riskier securities might change in either direction as opinion diverges. Our model shows that investor expectations of asset payoffs determine whether the optimists (called speculators and defined as purchasers of upstate claims) constitute a majority or a minority, and finds equilibria for both cases. Our model also identifies uniquely different conditions that imply increased returns under one set of conditions, decreased returns on another.

\subsection{Dynamic Analyses}

Other heterogeneous expectations models investigate equilibria in which investors respond immediately and strategically to an evolving environment. For example, Harrison and Kreps (HK) [6] show that equilibrium prices depend on how investors believe others will respond to their actions. HK [6] show further that if an equilibrium price exists in their model, it will exceed the price any investor would be willing to pay if obliged to hold the stock forever. In this context of reactive trading, heterogeneity increases potential profit opportunities because 
investors believe they can profit from what they view as the irrationality of others. As already mentioned, in our model investors accept an equilibrium ruling price as given, and in that context the HK complications do not apply.

DeTemple and Murthy (DTM) [7] examine interest rates, asset prices, and asset holdings in an economy with heterogeneous and rationally updated beliefs. The equilibrium interest rate becomes a weighted average of the rates that would prevail in economies with homogeneous agents who hold the beliefs of different agents in the heterogeneous model. The weights are fractions of total wealth held. In DTM [7] financial innovation affects both quantity and price dynamics. Irrational investors are eventually bankrupted through trading with their rational counterparts, but only after a very long time; several hundred years in one example.

Xiong and Yan (XY) [8] study dynamic equilibria in bond markets, assuming two groups of investors with different learning models. Since the groups are motivated to take speculative positions against each other, investor activity generates wealth fluctuations that increase asset price volatility and contribute to time variation in risk premia. By choosing particular parameters for their learning models, XY [8] isolate belief-dispersion effects from such other effects as erroneous average belief and underestimation of risk. Their work explains excessive volatility in bond yields, the failure of the expectations hypothesis, and the ability of a linear combination of forward rates to predict bond returns.

Neave [9] assumes investors are passive price-takers who use options to trade in an incomplete market. As options become closer substitutes for contingent claims, the incomplete markets equilibria converge smoothly to complete markets equilibria when investors behave as price takers. These results contrast with the Brock, Hommes, and Wagener [10] conclusion that hedging instruments can destabilize markets when traders react to each other.

This paper provides a theory capable of explaining both the traditional approach to valuation and departures from it. We assume heterogenous investors and the way their differences are resolved at equilibrium.

\subsection{Selected Empirical Findings}

Campbell, Giglio and Polk (CGP) [2] find that the stock market downturns of 2000-2002 and 2007-2009 have different proximate causes. CGP [2] attribute the early 2000s downturn to a large increase in the discount rates applied to profits by rational investors, while they attribute the late 2000 s crash to a decrease in rational expectations of future profits. Our model provides a theoretical setting in which both discount rate and cash flow expectations can be identified and analyzed separately. Although we focus primarily on risk neutral investors, an Appendix finds a complete market equilibrium with risk averse investors. And the model can be extended further to distinguish between changes in discount rates and changes in expectations, although apart from an illustrative example we do not do so in this paper.

Asness, Moskowitz and Pedersen (AMP) [11] examine value and cross-sectional 
momentum strategies across a wide variety of instruments and markets, finding that momentum loads positively on liquidity risk but negatively on value. AMP [11] suggest their results might be due to momentum in the most popular trades, as investors flock to assets whose prices have appreciated most recently. When a liquidity shock occurs, investors engaged in liquidating sell-offs will put more price pressure on the most popular and crowded trades. High momentum securities will be popular initially, but will also be securities from which everyone runs at the same time [12]. On the other hand, value purchases can represent a contrarian view that is less affected by the liquidity concerns surrounding the most popular assets. This paper's model can incorporate either liquidity or value effects, and different price patterns emerge according to investors' perception of an information event; i.e., the extent to which different investors interpret the same message differently.

Moskowitz, Ooi, and Pedersen (MOP) [3] document significant time series momentum in markets for 58 liquid securities. MOP [3] find persistence in returns over one to 12 months, and partial reversals over longer horizons. MOP [3] further find that while time series momentum strategies can generate substantial abnormal returns, such portfolios have little exposure to standard asset pricing factors. The MOP [3] momentum strategies perform best during extreme markets, and portfolio profits accrue primarily to speculators at the expense of hedgers.

MOP [3] note that time series momentum matches predictions of both behavioral and rational asset pricing theories. Generally, behavioral theories envisage momentum as deriving from an initial underreaction to news followed by an upward drift and eventual overreaction, with undervaluation driven by conservatism and subsequent overvaluation based on representativeness (Barberis, Shleifer and Vishny [13]). The levels of these and other behavioral characteristics may be affected by investor sentiment (Baker and Wurgler [14]). Brown, Christensen, Elliott, and Mergenthaler [15] studied managers' financial reporting practices in relation to the BW sentiment index. On the other hand, MOP do not find sentiment effects in their data. Positive feedback trading is a related behavior-based theory of momentum, arising from self-attribution bias and overconfidence. This momentum is augmented as rational investors "jump on the bandwagon" to exploit a price runup while it lasts (DeLong, Shleifer, Summers, and Waldmann [16]). Price reversals eventuate when momentum collapses.

Rational theories usually view momentum as a reaction to changes in risk, and various risk proxies have also been studied. These include stochastic discount factor (Ahn, Conrad, and Dittmar [17]), dividend growth rate changes (Johnson [18]), firm revenue and cost volatility (Sagi and Seasholes [19]).

Although our model prices only two contingent claims, its structure provides insights into more broadly defined securities markets. We allow learning abilities to differ as primitives in our model, and explains momentum as a rational response of investors with different learning abilities and different strategies. It is in the rational camp since momentum can be interpreted as an initial reaction to 
an information event. However, since momentum pricing eventually reverses, it assumes further that momentum investors return to rational investing in equilibrium.

\section{Model Structure}

Our model adapts a structure developed by Fostel and Geanakoplous (FG) [20]. In a single period version, equilibrium is sought in a two-state complete markets setting with a continuum of rational risk-neutral investors. ${ }^{1}$ In this and the following section, investors are assumed to agree on the sizes of state payoffs (fundamentals), but not on state probabilities (expectations). ${ }^{2}$ Equilibrium prices are established by a marginal investor, and other investors trade at the marginal investor's price.

\subsection{State Payoffs, Expectations, and Utility}

Our single-period model considers times zero and one. At time zero the economy has a productive asset $X$ that produces $U$ units of a consumption good at time 1 if a high state occurs and $D$ units in the low state, $U>D>0$. There is a continuum of investors $h \in(0,1)$. Each investor is endowed with both upstate and downstate contingent claims, upstate with density $U$ and downstate with density $D$. Investors trade claims to maximize the expected utility of their endowment. Information and processing costs are assumed to be zero.

For simplicity, we assume the objective probabilities of realizing $U$ and $D$ are equal. ${ }^{3}$ When for comparison purposes we postulate investors with homogeneous expectations, they will be assumed to use these equal probabilities. As to heterogeneous expectations, each investor $h \in[0,1]$ is assumed to have subjective probabilities $\left(q_{U}(h), q_{D}(h)\right)$ such that

$$
q_{U}(h)+q_{D}(h)=1,
$$

for the realized state at $t=1$. We further assume that $q_{U}(h)$ is a monotonically and strictly increasing function of $h$; hence $q_{D}(h)=1-q_{U}(h)$ is strictly monotonically decreasing. ${ }^{4}$

To depict the impacts of changing expectations as simply as possible, we employ linear functions $q_{U}(h)$ and $q_{D}(h)$ whose details will be specified shortly. We model a change in average investor expectations as a shift of the upstate probability function, and a change in agreement between investors as a change in the upstate function's slope.

Denote the investors' consumption levels at time 1 by $C_{U}$ and $C_{D}$, where

$$
\int_{0}^{1} C_{U}^{h} \mathrm{~d} h=U
$$

\footnotetext{
${ }^{1}$ We later show that with risk averse investors the equilibrium has a similar qualitative structure. ${ }^{2}$ We can also study changes in state payoffs, but apart from one example do not do so in this paper. ${ }^{3}$ Asset prices in Arrow-Debreu equilibria depend only on subjective probabilities. But we need objective probabilities for comparison purposes; see Section 4.

${ }^{4}$ Weak monotonicity is only minimally restrictive since it can be established by re-ordering investors. We assume strong monotonicity for analytic convenience.
} 


$$
\int_{0}^{1} C_{D}^{h} \mathrm{~d} h=D
$$

We assume in attaining equilibrium, that all investors are risk-neutral and that each maximizes an expected utility:

$$
U^{h}\left(C_{U}, C_{D}\right)=q_{U}(h) C_{U}+q_{D}(h) C_{D} .
$$

Thus claims are valued at time zero using the equilibrium prices $p_{U}$ and $p_{D}$ respectively; transactions costs are assumed to be zero. Purchases are restricted to the value of the cash raised; investors are not permitted to sell short. At equilibrium, investor $h_{1}$ is defined as the marginal buyer who is indifferent between buying up or down claims at the prices $p_{U}$ and $p_{D}$. Using (1) and (2), it is easy to verify that investors $h \in\left[h_{1}, 1\right)$ will buy only upstate claims, and investors $h \in\left(0, h_{1}\right)$ only downstate claims. Consistent with prior literature, we call the former investors speculators, the latter hedgers. ${ }^{5}$ The speculators' cash constraint ${ }^{6}$ is

$$
\int_{h_{1}}^{1}\left(U p_{U}+D p_{D}\right) \mathrm{d} h=\left(U p_{U}+D p_{D}\right)\left(1-h_{1}\right)=U p_{U}
$$

while the hedgers' is

$$
\int_{0}^{h_{1}}\left(U p_{U}+D p_{D}\right) \mathrm{d} h=\left(U p_{U}+D p_{D}\right)\left(h_{1}\right)=D p_{D}
$$

Since speculators and hedgers transact with each other, and since our market economy is assumed to be closed, equating revenues with expenditures for either class of traders defines the exchange of funds for both.

\subsection{Equilibrium}

Equilibrium is defined by investor proportions $\left(h_{1}, 1-h_{1}\right)$. Since the marginal buyer $h_{1}$ is indifferent to buying the up or the down claim, the equilibrium must satisfy

$$
\frac{q_{U}\left(h_{1}\right)}{p_{U}\left(h_{1}\right)}=\frac{q_{D}\left(h_{1}\right)}{p_{D}\left(h_{1}\right)} .
$$

It is convenient to rewrite (5) as

$$
\frac{p_{U}\left(h_{1}\right)}{p_{D}\left(h_{1}\right)}=\frac{q_{U}\left(h_{1}\right)}{q_{D}\left(h_{1}\right)},
$$

thus distinguishing cash constraint from expectations effects. To interpret the cash constraint side of (6), note that for any $h_{1} \in(0,1)$ both sides of (3) and (4) are positive quantities. Hence we can take the ratio of (3) to (4) to write

$$
P(h) \equiv \frac{p_{U}(h)}{p_{D}(h)}=\frac{D(1-h)}{U h}
$$

${ }^{5}$ Empirically, hedgers are primarily large commercial firms while speculators are large investment houses.

${ }^{6}$ The cash constraints represent aggregates of individual investors' budget constraints. Investors may repurchase some of the securities they first sell. FG [20] assume this trading pattern for analytical convenience, and we retain it, even though in the present context it is equally convenient to consider only net trading. 
with $P(h)$ defining the price impact of the cash constraints for any investor $h \in(0,1)$. Note that $P(h)$ increases with $U$. That is, holding probabilities constant, fewer high-state claims increase their price.

Note also from (7) that since $P(1 / 2)=D / U<1$, a necessary condition for an equilibrium with $P>1$ is

$$
(1-h)>h,
$$

which implies proportionately more speculators than hedgers. The condition further implies that due to the influence of heterogeneous expectations, the equilibrium prices typically incorporate (positive or negative) risk premia. We write the expectations side of (6) as

$$
Q(h) \equiv \frac{q_{U}(h)}{q_{D}(h)} .
$$

Then treating $D$ and $U$ as fixed, equating the expressions in (7) and (8) permits finding the equilibrium value $h_{1}$, from which $P\left(h_{1}\right), p_{U}\left(h_{1}\right), p_{D}\left(h_{1}\right), Q\left(h_{1}\right), q_{U}\left(h_{1}\right)$, and $q_{D}\left(h_{1}\right)$ can all be determined. Note that changing expectations can only affect equilibrium prices and quantities if the marginal investor is affected. The risk premia are a consequence of the equilibrium condition $Q\left(h_{1}\right)=P\left(h_{1}\right)$.

Henceforth, we denote the equilibrium claim price ratio using $P_{e 1} \equiv P\left(h_{1}\right)$. After a parameter change a new equilibrium will be denoted by $P_{e 2}$. Similarly, we denote the original equilibrium ratio of speculators to hedgers by $H_{e 1} \equiv\left(1-h_{1}\right) / h_{1}$; and after a parameter change by $H_{e 2}$.

\subsection{Interpreting the Cash Constraints}

For any $h \in(0,1)$, (7) can be rewritten

$$
\frac{(1-h)}{h}=\frac{U p_{U}(h)}{D p_{D}(h)}
$$

cash constraints require that the ratio of speculators to hedgers equal the ratio of upside to downside expenditures on claims. Since (9) further implies that

$$
h=\left(\frac{D p_{D}}{U p_{U}+D p_{D}}\right) ; 1-h=\left(\frac{U p_{U}}{U p_{U}+D p_{D}}\right)
$$

$h$ and $1-h$ can be interpreted as relative expenditure on hedging and speculation respectively. Since with risk neutral investors and zero time preference, equilibrium claim prices always satisfy $p_{U}>0, p_{D}>0, p_{U}+p_{D}=1$,

$$
D<D p_{D}+U p_{U}<U
$$

the total value of securities expenditures increases with $p_{U}$. In (9), (10), and (11) equilibrium values are obtained by setting $h=h_{1}$.

\section{Analyzing Myopic Equilibria}

This section first shows that any change in $Q$, the ratio of investor expectations, defines an equilibrium change that is observationally distinct from one following on a change in $P$. The second subsection defines the rotations representing 
changes in investor agreement.

\subsection{The $Q$ and $P$ Functions}

Figure 1 graphs $Q(h)$ and $P(h)$ as defined by (7) and (8). The Figure uses generic properties of $P(h)$ and $Q(h)$ retained throughout the paper.

Rewriting (8) as

$$
Q(h)=\frac{q_{U}(h)}{q_{D}(h)}=\frac{1-q_{D}(h)}{q_{D}(h)}=\frac{1}{q_{D}(h)}-1 .
$$

and recalling that $q_{D}^{\prime}(h)<0$ establishes $Q^{\prime}(h)>0 ; Q^{\prime \prime}(h)>0$, as drawn in Figure 1. Similarly, rewriting (7) as

$$
P(h)=\left(\frac{D}{U}\right)\left(\frac{1}{h}-1\right)
$$

and treating $U$ and $D$ as parameters establishes $P^{\prime}(h)<0, \quad P^{\prime \prime}(h)>0$. Although subsequent analyses will modify either or both $Q$ and $P, Q(h)$ will remain strictly increasing strictly convex, and $P(h)$ strictly decreasing strictly convex throughout the paper.

\subsection{Changes in $Q$ and in $P$}

Following an ambiguous information event, we interpret increasing agreement as a clockwise rotation of a linear upstate probability function. Investors may relocate themselves along the continuum. Given increasing agreement, some high state investors will lower their prior upstate probabilities, but not so much as to abandon their high state investment strategy. Other high state investors may switch to a low state investment strategy. Similarly, some low state investors may raise their prior high state probabilities sufficiently to switch to a high state investment strategy while others retain low state expectations.

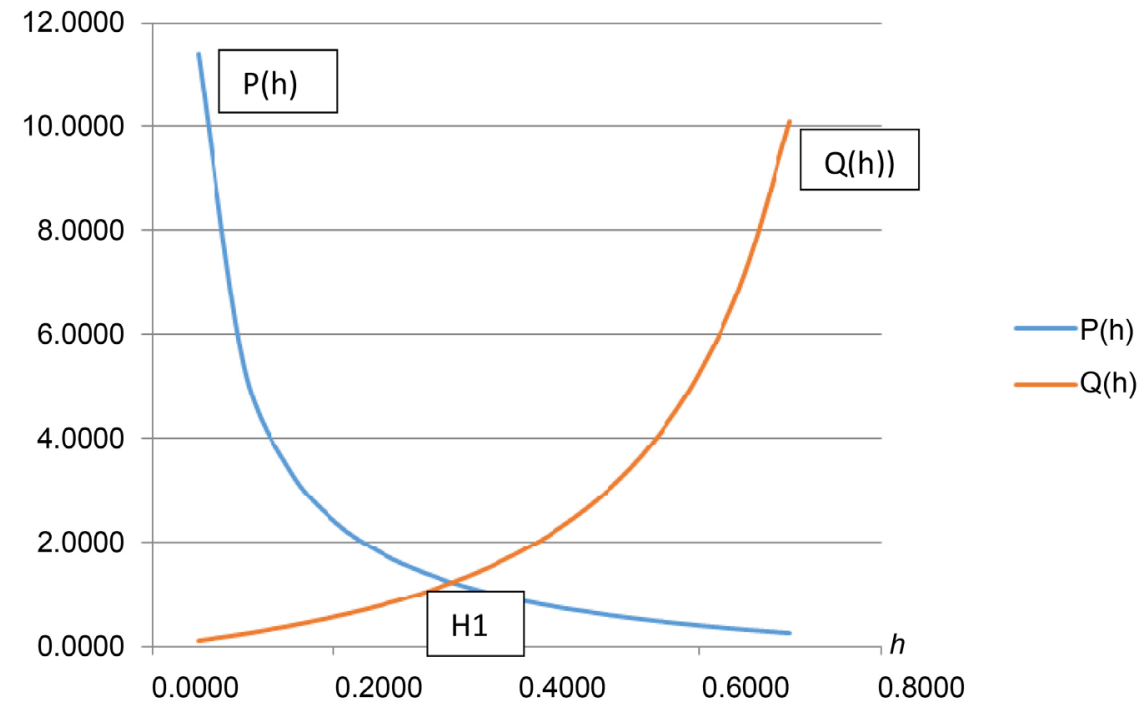

Figure 1. $P(h), Q(h)$ and equilibrium. This figure depicts a market equilibrium for generic forms of $P(h)$ and $Q(h)$. 
If the proportion of speculators making different adjustments remains the same as before, any rotation of $Q$ is about $h_{1}$. In this case the marginal investor and claim prices would not change, but investors with different strategies could still react differently. For example, we would expect that investors following a momentum strategy would have different prior probabilities than those following a value strategy, contributing to different investment decisions. To the extent that an information event increases the upstate probability of all investors $q_{u}(h)$ will shift up, and vice versa. In subsequent analyses we omit this possibility and concentrate on rotations attributable to ambiguous information events.

Rotation of the expectations function will not normally be around the existing marginal investor. If the rotation is counter clockwise and greater than $h_{1}$, a greater proportion of investors will raise their upstate probabilities. The probability of the new marginal investor $h_{2}<h_{1}$; the proportion of speculators increases with the information being interpreted as favorable news by most investors. Alternatively, if the rotation is counter clockwise and $h_{3}>h_{1}$, the proportion of investors lowering their upstate probabilities increases relative to the original position and the information event is interpreted as bad news by most investors. In the rest of paper we shall study increasing agreement, in which case all rotations will be clockwise.

\subsection{Information Processing and Changing Expectations}

The graphs in this section outline our model and its evolving equilibrium prices. Since there is a one-to-one mapping from rotations of $q_{u}(h)$ to those of $Q_{u}(h)$ we work with the latter in the graphs below.

Figure 2 indicates an initial equilibrium for which $Q_{2}\left(h_{2}\right)<Q_{1}\left(h_{1}\right)$, as the result of an information event ${ }^{7}$ regarding which investor agreement increases. This means that $Q_{2}$ slopes less steeply than $Q_{1}$, rotating clockwise around an intersection between $Q_{1}(h)$ and a horizontal, homogeneous expectations line (for clarity the latter is not shown). Under these assumptions, the new $Q_{2}(h)$ determines an equilibrium price ratio $P_{e 2}$ such that $P_{e 1}<P_{e 2}<P^{*}$, where $P^{*}$ refers to the homogeneous expectations price. The proportion of speculators also increases, in an amount dependent on the elasticity of $Q_{2}(h)$. Depending on initial choices of data, the increased upstate claim purchases may be associated with either value or momentum criteria, according to how individual investors react to the information event. In a series of such adjustment processes, successive rotations reduce the slope in a series of steps that eventually bring $Q_{t}$ closer to the horizontal (homogeneous expectations) line.

What sort of information event could trigger the behavior in Figure 2? An ambiguous information release (e.g., a central bank discussion of monetary policy) could cause speculators to lower their upstate probabilities and hedgers to increase theirs. As a result, investor agreement increases. If the resulting locus of ${ }^{7}$ The slope determined by the difference equation is a constant value affecting the linear function $q(h)$. But it is reflected in $Q(h)$ as a changing value, because $Q(h)=q(h) /(1-q(h))$ is nonlinear. 


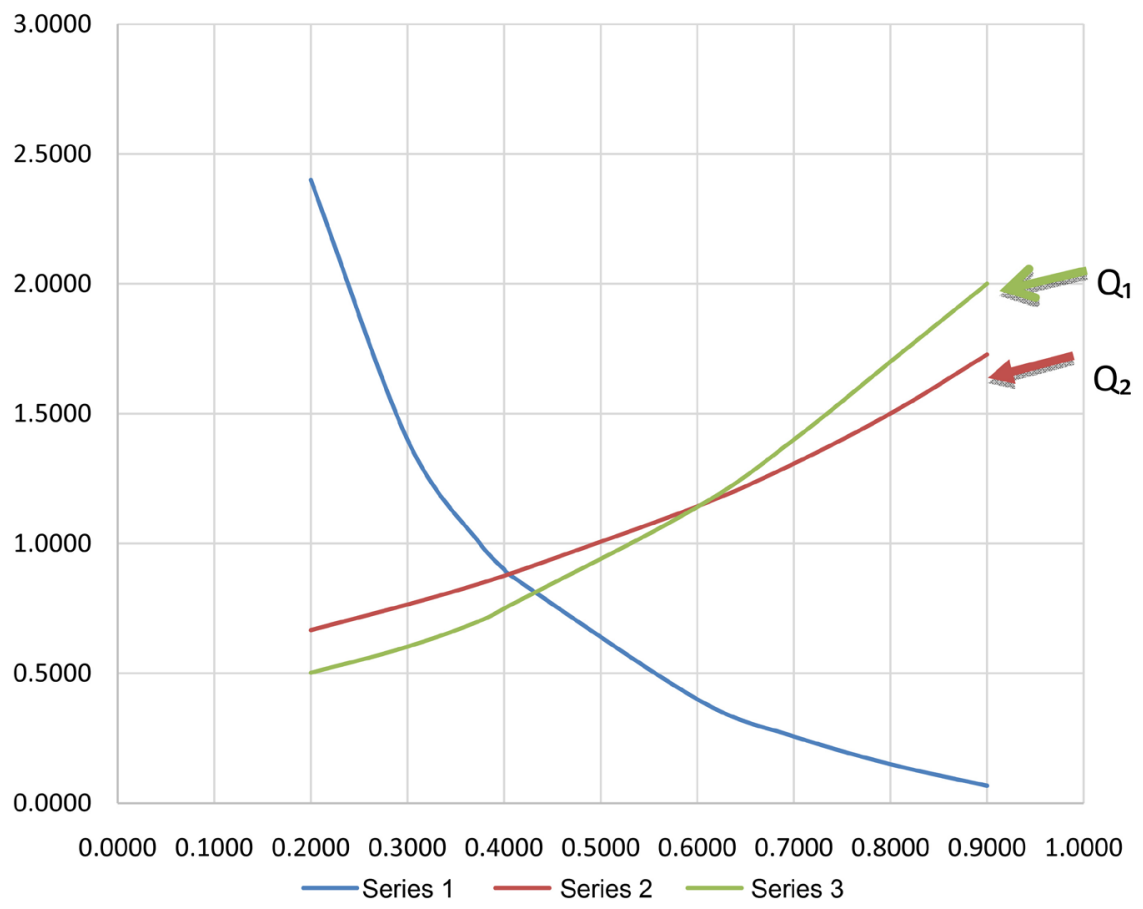

Figure 2. Upstate price increase.

rotation is as shown in Figure 2, the upstate probability for the marginal investor decreases, the marginal investor moves to the left in the Figure, the number of speculators increases, and the greater speculative demand increases upstate claim prices.

Now consider a price decrease. In this case, suppose that after an information event occurs, $Q(h)$ rotates clockwise with a locus of rotation $h_{2}<h_{1}$ as shown by the intersection in Figure 3. The equilibrium price ratio decreases, $P_{e 1}>P_{e 2}>P^{*}$, and speculative purchases also decrease. As before, these changes could be associated either with sale of an overvalued asset as represented by a reversal of contrarian purchases or by sales following on declining momentum criteria.

To further interpret Figure 3, suppose a different information event, one that is interpreted as bad news by most speculators and hedgers (e.g., a forecast of bad news regarding real sector performance). At the same time, a minority takes a contrarian view, believing that the forecast is an attempt to lower market expectations. Again, investor agreement increases, but the new locus of rotation is at a lower point $h_{2}<h_{1}$, the new marginal investor increases and the proportion of speculators decreases as do upstate claim prices. Complementing Miller's (1977) argument that prices of riskier securities might change in either direction as opinion diverges, we have suggested that the ambiguity of an information event-signalled by a decrease in the slope of $q_{u}(h)$-will be a determinant of market behavior. Furthermore, a specific information event could lead to either an increase, a decrease, or no change in price.

We can also use Figure 3 to analyze the finding of CGP [2] that the price impacts 


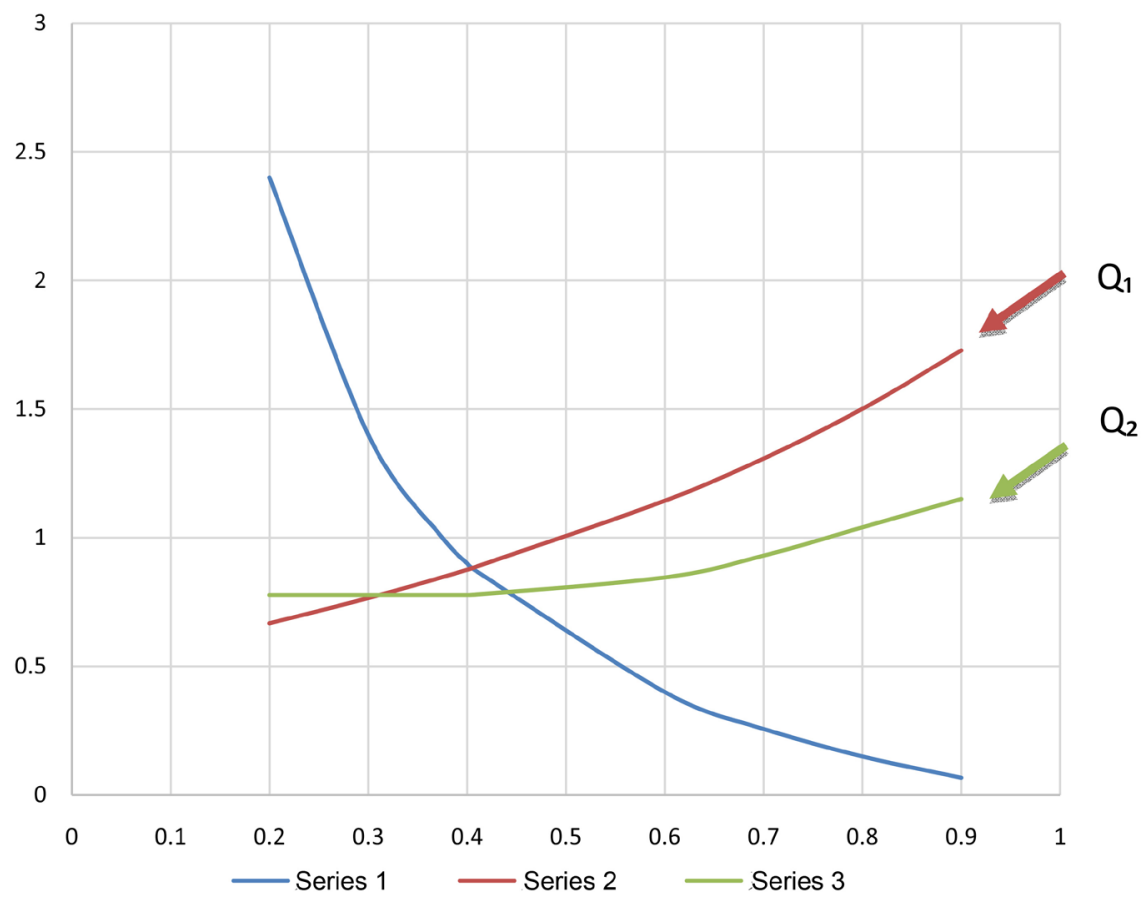

Figure 3. Upstate price decrease.

of the 2000-2002 tech crash were due principally to changes in discount rates rather than in expectations. A major contributing factor to the crash was a collapse of investor confidence due to numerous financial reporting failures (e.g., Enron, WorldCom, Nortel), all of which contributed to increased perceptions of market risk (investors bear market risk in our risk neutral economy unless claim prices are equal). Booming markets leading up to the crash created an increasing proportion of speculators, particularly in shares of (presumed high payoff) high tech companies. An increasing discount rate would lower speculators' expectations closer to those of hedgers, driving a clockwise rotation of $Q(h)$. The result is a reduction in upstate prices and a lower proportion of speculators.

CGP [2] also report that the price impacts in early stages of the 2007-2009 crash were due principally to changes in fundamentals (cash flow forecasts). As noted in Section 2.3 our model can also analyze this finding, but with a different approach. Arguably, boom times leading up to 2007 resulted in a large proportion of speculators. As market failures mounted in 2007, expected cash flows for all firms fell, with those of high payoff firms particularly affected. From (7), holding expectations constant, the result is to shift $P(h)$ upward. This shift of $P(h)$ leads to a lower proportion of speculators, with resulting fall in the share prices of former high payoff firms.

\section{Conclusion}

We have presented a model in which investors have heterogeneous state probabilities and face message ambiguity. The model provides theoretical support for a variety of empirical observations, and empirical investigation is now needed to 
assess the likelihood of different adjustment patterns. Particular patterns of price variation seem likely to characterize individual markets, and patterns may change from one point in time to another. At the same time, however, combinations of patterns may also occur, stimulated by particular combinations of circumstances. In some analyses, we might further expect positive correlation between changes in investor probabilities and in payoffs. Arguably, for most investors high payoff expectations also fell in subsequent stages of the crash. Scrutiny of Figure 3 shows, if so, the two effects reinforce each other. We leave these matters to future papers.

\section{Conflicts of Interest}

The authors declare no conflicts of interest regarding the publication of this paper.

\section{References}

[1] Figlewski, S. (2008) Estimating the Implied Risk Neutral Density for the U.S. Market Portfolio. In: Bollerslev, T., Russell, J.R. and Watson, M., Eds., Volatility and Time Series Econometrics. Essays in Honor of Robert F. Engle, Oxford University Press, Oxford.

[2] Campbell, J.Y., Stefano, G.W. and Polk, C. (2012) Hard Times. AFA 2012 Chicago Meetings Paper. https://doi.org/10.2139/ssrn.1787000 http://ssrn.com/abstract $=1787000$

[3] Moskowitz, T.J., Ooi, T.H. and Pedersen, L.H. (2011) Time Series Momentum. Chicago Booth Research Paper No. 12-21. Fama-Miller Working Paper. https://doi.org/10.2139/ssrn.2089463 http://ssrn.com/abstract=2089463

[4] Haltiwanger, J. and Waldman, M. (1985) Rational Expectations and the Limits of Rationality: An Analysis of Heterogeneity. The American Economic Review, 75, 326-340.

[5] Miller, E.M. (1977) Risk, Uncertainty, and Divergence of Opinion. Journal of Finance, 32, 1151-1168. https://doi.org/10.1111/j.1540-6261.1977.tb03317.x

[6] Harrison, J.M. and Kreps, D.M. (1978) Speculative Investor Behavior in a Stock Market with Heterogeneous Expectations. Quarterly Journal of Economics, 92, 323-336. https://doi.org/10.2307/1884166

[7] Detemple, J. and Murthy, S. (1994) Intertemporal Asset Pricing with Heterogeneous Beliefs. Journal of Economic Theory, 62, 294-320. https://doi.org/10.1006/jeth.1994.1017

[8] Xiong, W. and Yan, H. (2010) Heterogeneous Expectations and Bond Markets. Review of Financial Studies, 23, 1433-1466. https://doi.org/10.1093/rfs/hhp091

[9] Neave, E.H. (2015) Heterogeneous Expectations and Option Pricing in an Incomplete Market. Queen's University Working Paper.

[10] Brock, W.A., Hommes, C.H. and Wagener, F.O.O. (2006) More Hedging Instruments May Destabilize Markets. Working Paper 06-11. Warwick Business School, Finance Group.

[11] Asness, C.S., Moskowitz, T.J. and Pedersen, L.H. (2013) Value and Momentum Everywhere. The Journal of Finance, 68, 929-985. https://doi.org/10.1111/jofi.12021 
[12] Pedersen, L.H. (2009) When Everyone Runs for the Exit. The International Journal of Central Banking, 5, 177-199. https://doi.org/10.3386/w15297

[13] Barberis, N., Shleifer, A. and Vishny, R. (1998) A Model of Investor Sentiment. Journal of Financial Economics, 49, 307-343. https://doi.org/10.1016/S0304-405X(98)00027-0

[14] Baker, M. and Wurgler, J. (2007) Investor Sentiment in the Stock Market. Journal of Economic Perspectives, 21, 129-152. https://doi.org/10.1257/jep.21.2.129

[15] Brown, N.C., Christensen, T.E., Elliott, W.B. and Mergenthaler, R.D. (2012) Investor Sentiment and Pro-Forma Earnings Disclosures. Journal of Accounting Research, 50, 1-40. https://doi.org/10.1111/j.1475-679X.2011.00427.x

[16] DeLong, J.B., Shleifer, A., Summers, L. and Waldmann, R.J. (1990) Positive Feedback Investment Strategies and Destabilizing Rational Speculation. Journal of Finance, 45, 375-395. https://doi.org/10.1111/j.1540-6261.1990.tb03695.x

[17] Ahn, D.-H., Conrad, J. and Dittmar, R.F. (2003) Risk Adjustment and Trading Strategies. Review of Financial Studies, 16, 459-485. https://doi.org/10.1093/rfs/hhg001

[18] Johnson, T.C. (2002) Rational Momentum Effects. Journal of Finance, 57, 585-608. https://doi.org/10.1111/1540-6261.00435

[19] Sagi, J.S. and Seasholes, M.S. (2007) Firm-Specific Attributes and the Cross-Section of Momentum. Journal of Financial Economics, 84, 389-434. https://doi.org/10.1016/j.jfineco.2006.02.002

[20] Fostel, A. and Geanakoplos, J. (2011) Why Does Bad News Increase Volatility and Decrease Leverage? Journal of Economic Theory, 147, 501-525.

https://doi.org/10.1016/j.jet.2011.07.001 


\section{Appendix: Equilibrium with Risk Averse Investors}

This Appendix shows that in the complete market of this paper investor risk aversion will reduce both the upstate equilibrium price and speculators' purchases relative to their risk neutral values. The changes follow from a downward shift of the $Q$ curve as established in this note, and depicted in the graph below. (The effect in the graph is exaggerated to show it more clearly.) In addition, the magnitude of the downward shift can be assessed using the utility function's Arrow-Pratt index of risk aversion. Finally, we note that the model can distinguish the equilibrium effects of changes in risk aversion from changes in market risk.

Each investor $h$ faces the expected utility maximization problem of allocating a fixed endowment between two contingent claims:

$$
\max _{C}\left\{q_{U} V\left(C_{U}\right)+q_{D} V\left(C_{D}\right)\right\}
$$

subject to

$$
p_{U} U+p_{D} D=F
$$

where $V$ is a utility function, $C_{U}$ is consumption in the upstate, $C_{D}$ in the downstate, $F$ a fixed endowment ${ }^{14}$ and $p_{U}, p_{D}$ are equilibrium prices for contingent claims with payoffs $U$ and $D$ respectively. For any investor $h$ the first order necessary conditions for $C_{U}$ and $C_{D}$ are:

$$
\begin{aligned}
& q_{U} V^{\prime}\left(C_{U}\right)=\lambda p_{U} \\
& q_{D} V^{\prime}\left(C_{D}\right)=\lambda p_{D}
\end{aligned}
$$

where $\lambda$ is a Lagrange multiplier. Since all terms in Equation (A2.2) are positive, the equations' ratio can be taken to obtain

$$
q_{U} V^{\prime}\left(C_{U}\right) / q_{D} V^{\prime}\left(C_{D}\right)=p_{U} / p_{D} .
$$

For a risk-neutral investor $h$, marginal utility is constant and (A2.3) can be simplified to

$$
q_{U} / q_{D}=p_{U} / p_{D} .
$$

A solution to (A2.4) defines $h_{1}$, the marginal risk neutral investor, ${ }^{15}$ who by satisfying the optimality conditions will be indifferent between buying an upstate or a downstate claim. Specifically, the marginal investor satisfies:

$$
Q\left(h_{1}\right) \equiv q_{U}\left(h_{1}\right) / q_{D}\left(h_{1}\right)=p_{U}\left(h_{1}\right) / p_{D}\left(h_{1}\right) \equiv P\left(h_{1}\right) .
$$

with linear utility, it is easy to show that other risk neutral investors $h \in\left(0, h_{1}\right]$ buy only the downstate claim, and investors $h \in\left(h_{1}, 1\right)$ buy only the upstate claim.

Now, leaving all other features of the model unchanged, suppose that for every investor $h$ risk aversion is determined by the same strictly concave strictly increasing utility function. In this case the necessary optimality conditions revert to (A2.3).

Denoting risk averse expectations with an asterisk, it follows from diminish- 
ing marginal utility that for all $h$ the left-hand side of (A2.3) is less than in the risk neutral case:

$$
Q^{*}(h) \equiv q_{U}(h) V^{\prime}\left(C_{U}\right) / q_{D}(h) V^{\prime}\left(C_{D}\right)<q_{U}(h) / q_{D}(h) \equiv Q(h) .
$$

At the risk neutral equilibrium $Q\left(h_{1}\right)=P\left(h_{1}\right)$. And since $Q^{*}(h)<Q(h)$ for all $h$, we must have $Q^{*}\left(h_{1}\right)<P\left(h_{1}\right)$. Then since $Q^{*}$ is increasing, and $P$ decreasing in $h$, a new equilibrium $h_{2}$ as defined by (A2.3), must be such that $h_{2}>h_{1}$. Moreover, $Q^{*}\left(h_{2}\right)=P\left(h_{2}\right)<P\left(h_{1}\right)=Q\left(h_{1}\right)$. The relations between $P, Q, Q^{*}, h_{1}$ and $h_{2}$, are shown in the diagram below.

As with risk neutrality, the new marginal investor $h_{2}$ is indifferent between purchasing the upstate or the downstate claim because the claims' expected utilities are equal for investor purchases made at $p_{U}\left(h_{2}\right)$ and $p_{D}\left(h_{2}\right)$ respectively; i.e., $q_{U}\left(h_{2}\right) V(U)=q_{D}\left(h_{2}\right) V(D)$.

To ensure that the new equilibrium satisfies all other investors' utility maximization criteria, note that by the structure of the model $q_{U}(h)$ remains strictly monotone increasing in $h$. Hence the expectation of a speculator $h>h_{2}$ and buying the upstate claim is

$$
q_{U}(h)>q_{U}\left(h_{2}\right)
$$

and her expected utility

$$
q_{U}(h) V(U)>q_{U}\left(h_{2}\right) V(U) ; h>h_{2} .
$$

Similarly $q_{D}=1-q_{U}$ is strictly monotone decreasing and the expectation of a hedger $h<h_{2}$ is

$$
q_{D}(h)>q_{D}\left(h_{2}\right)
$$

and her expected utility is

$$
q_{D}(h) V(D)>q_{D}\left(h_{2}\right) V(D) ; h<h_{2} .
$$

Just as in the risk-neutral environment, because of the monotonicity of their expectations functions non-marginal purchasers are satisfied with their positions and cannot improve them by changing their purchases at current equilibrium prices $p_{U}\left(h_{2}\right), p_{D}\left(h_{2}\right)$.

To show how the shift from $Q$ to $Q^{*}$ can be assessed quantitatively, rewrite both the numerator and denominator of the ratio of marginal utilities using first-order Taylor expansions about the mean (assuming higher-order terms can be ignored). Defining $m=(U+D) / 2$, the ratio of marginal utilities can thus be written

$$
\begin{aligned}
V^{\prime}(U) / V^{\prime}(D) & =\left[V^{\prime}(m)+(U-m) V^{\prime \prime}(m)\right] /\left[V^{\prime}(m)-(m-D) V^{\prime \prime}(m)\right] \\
& =[1-\delta r(m)] /[1+\delta r(m)]
\end{aligned}
$$

where $\delta \equiv U-m=m-D$ and $r(m) \equiv-V^{\prime \prime}(m) / V^{\prime}(m)$ is the Arrow-Pratt index of absolute risk aversion. Note that when risk aversion is introduced the reduction in $p_{U}$ (relative to a risk neutral equlibrium) cannot be greater than indicated by (A2.5). On the other hand, (A2.5) decreases as the Arrow-Pratt index increases, so the gap between $Q$ and $Q^{*}$ increases as risk aversion increases. 
Since changes in risk aversion affect $Q^{*}$, and since earlier work has shown that changes in risk affect $P$, the model can distinguish the effects of the two types of change. Moreover, if the utility's risk aversion index can be determined independently of the model, it is also possible to determine whether a shift in the original function $Q$ is caused by a change in expectations, by a change in risk preferences, or by a combination of the two.

To illustrate the effect of a change in risk preferences in the economy on upstate claim purchases, we show below that

$$
\frac{\mathrm{d} C_{U}}{\mathrm{~d} r}=\frac{\lambda p_{D}^{2} p_{U}}{|J|}\left[-r^{-1}\left(C_{U}\right)+r^{-1}\left(C_{D}\right)\right] .
$$

Since $\lambda>0$ and $|J|>0$, the coefficient of the bracketed term is positive. Note that if investors are constant absolute risk averse (CARA), the expression is zero. That is, changes in CARA investor risk preferences, even if economy-wide, do not affect their consumption decisions.

A more realistic assumption, however, is that investors are decreasing absolute risk averse (DARA). Then, we have $\mathrm{d} C_{U} / \mathrm{d} r<0$ if $C_{U}>C_{D}$ and $\mathrm{d} C_{U} / \mathrm{d} r>0$ if $C_{U}<C_{D}$, which indicates that both speculators and hedgers decrease their portfolio diversification as the level of $r$ decreases. If the level of $r$ continues to decrease, investor portfolios become increasingly specialized, approaching those of risk neutral investors.

To illustrate the effects of an increase in market risk on upstate claim demand, change the investor decision problem of this section by adding a mean-preserving spread, as follows:

$$
\max L_{C_{U}, C_{D}}=q_{U} V\left(C_{U}+\varepsilon\right)+q_{D} V\left(C_{D}-\varepsilon\right)+\lambda\left(F-p_{U} C_{U}-p_{D} C_{D}\right), \varepsilon>0 . \text { (A2.8) }
$$

It can then be shown, using Cramers rule, that

$$
\frac{\mathrm{d} C_{U}}{\mathrm{~d} \varepsilon}=\frac{p_{D}}{|J|}\left[q_{D} V^{\prime \prime}\left(C_{D}-\varepsilon\right) p_{U}+q_{U} V^{\prime \prime}\left(C_{U}+\varepsilon\right) p_{D}\right]<0 .
$$

Thus, the increased market risk leads to lower upstate demand, consistent with the risk neutral model. To interpret, consider the marginal investor. The increased upstate payoff makes upstate claim purchases more attractive to her, and downstate purchases correspondingly less attractive. Thus, the new marginal portfolio contains less upstate claims and more downstate, increasing the $q_{U} / q_{D}$ ratio. Other investors will react in a similar manner, pushing down the $Q^{*}$ curve to a new equilibrium on Figure A1 with lower upstate claim purchases and price. 


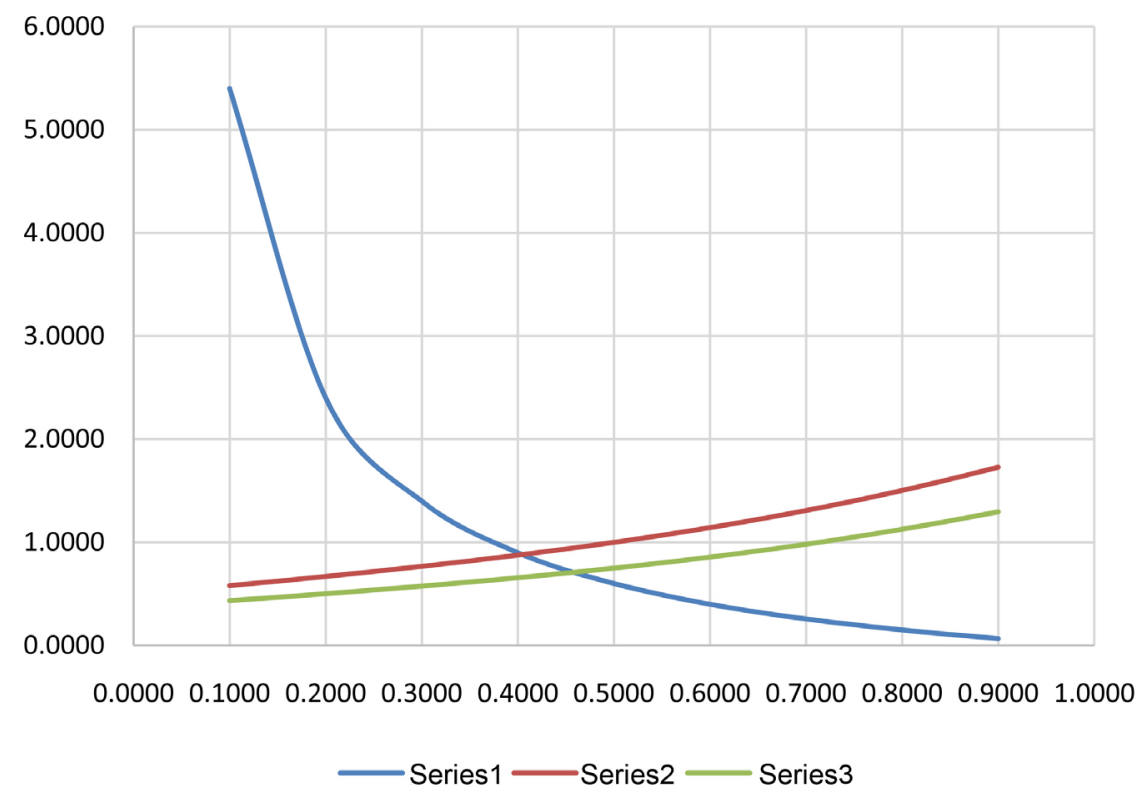

Figure A1. Equilibrium for risk neutral and risk averse investors. 